University of Nebraska - Lincoln

DigitalCommons@University of Nebraska - Lincoln

Faculty Publications from the Harold W. Manter Laboratory of Parasitology

1995

\title{
Libyostrongylus dentatus n. sp. (Nematoda: Trichostrongylidae) from Ostriches in North America, with Comments on the Genera Libyostrongylus and Paralibyostrongylus
}

Eric P. Hoberg

United States Department of Agriculture, Agricultural Research Service, geocolonizer@gmail.com

S. Lloyd

North Carolina State University at Raleigh

H. Omar

Texas A \& M University - College Station

Follow this and additional works at: https://digitalcommons.unl.edu/parasitologyfacpubs

Part of the Biodiversity Commons, Parasitology Commons, and the Terrestrial and Aquatic Ecology Commons

Hoberg, Eric P.; Lloyd, S.; and Omar, H., "Libyostrongylus dentatus n. sp. (Nematoda: Trichostrongylidae) from Ostriches in North America, with Comments on the Genera Libyostrongylus and Paralibyostrongylus" (1995). Faculty Publications from the Harold W. Manter Laboratory of Parasitology. 726.

https://digitalcommons.unl.edu/parasitologyfacpubs/726

This Article is brought to you for free and open access by the Parasitology, Harold W. Manter Laboratory of at DigitalCommons@University of Nebraska - Lincoln. It has been accepted for inclusion in Faculty Publications from the Harold W. Manter Laboratory of Parasitology by an authorized administrator of DigitalCommons@University of Nebraska - Lincoln. 


\title{
LIBYOSTRONGYLUS DENTATUS N. SP. (NEMATODA: TRICHOSTRONGYLIDAE) FROM OSTRICHES IN NORTH AMERICA, WITH COMMENTS ON THE GENERA LIBYOSTRONGYLUS AND PARALIBYOSTRONGYLUS
}

\author{
E. P. Hoberg, S. Lloyd ${ }^{\star}$, and H. Omar† \\ United States Department of Agriculture, Agricultural Research Service, Biosystematics and National Parasite Collection Unit, \\ BARC East, Building 1180, 10300 Baltimore Avenue, Beltsville, Maryland 20705-2350.
}

\begin{abstract}
Libyostrongylus dentatus $\mathbf{s p}$. $\mathrm{n}$. is described from ostriches on farms from North Carolina and Texas. Nematodes were recovered from the posterior proventriculus and under the koilon lining of the gizzard; the parasites occurred in mixed infections with Libyostrongylus douglassii. The species is distinguished from congeners by the presence of a prominent, dorsal, esophageal tooth; in males by the structure of the dorsal ray and spicules; and in females by small eggs (52-62 $\mu \mathrm{m}$ in length), a sublateral vulva situated at $93 \%$ of the body length from the anterior, and a strongly curled, digitate, tail with cuticular inflations at the anus. Conflicts in the generic diagnoses of Libyostrongylus and Paralibyostrongylus were apparent, based on the structure of the dorsal ray or position of rays 3-5 of the copulatory bursa. These can only be resolved based on phylogenetic analyses of the 11 nominal species referred to these genera.
\end{abstract}

Although historically represented only in North American zoos, various species of ratites (emus Dromaius novaehollandiae [Latham], rheas Rhea americana Linnaeus, and ostriches Struthio camelus Linnaeus) have been gaining economic importance in the United States and southern Canada. Semiconfined to near free-ranging flocks are now widely distributed on ranches across temperate North America. Concurrent with more intensive husbandry of these avian species has been the renewed recognition of parasitism by helminths as an influence on production, morbidity, and mortality, e.g., Thieler and Robertson (1915), Barton and Seward (1993), and Button et al. (1993). Also it has become apparent that a substantial component of the typical parasite faunas (principally strongylate nematodes) associated with these hosts has been introduced from sub-Saharan Africa and South America and some pathogenic species now may be widely established in North America (Table I). Although the parasite faunas of ratites appear to be host specific and historically defined by biogeographic and host associations (Clay, 1957), the potential for cross-transmission to domesticated birds or avian taxa endemic to North America has yet to be established (nor has the reciprocal been considered in detail). The greatest potential for transmission resides with strongylate nematodes with direct life cycles.

This burgeoning interest in ratites and their parasites has resulted in numerous submissions to the U.S. National Parasite Collection for confirmation or identification. Recently, material was submitted from isolated flocks of ostriches in North Carolina and Texas, with a provisional identification of Amidostomum sp. based on the presence of a prominent esophageal tooth extending into the buccal cavity. It was later determined that these specimens represented a previously unrecognized species of Libyostrongylus Lane, 1923 (Trichostrongylidae: Li-

Received 24 June 1994; revised 25 August 1994; accepted 25 August 1994.

* Department of Food Animal and Equine Medicine, College of Veterinary Medicine, North Carolina State University, Raleigh, North Carolina 27606.

$\dagger$ Department of Veterinary Pathobiology, The Texas Veterinary Medical Center, Texas A\&M University, College Station, Texas 778434467. byostrongylinae), which is described herein. Additionally, we provide the basis for readily distinguishing all species of $\mathrm{Li}$ byostrongylus from ostriches, enabling rapid diagnosis, and comment on diagnostic characters for the genera Libyostrongylus and Paralibyostrongylus Ortlepp, 1939.

\section{MATERIALS AND METHODS}

Specimens of Libyostrongylus were collected at the time of necropsy from 2 adult ostriches on farms in North Carolina and Texas. Nematodes were fixed in buffered $10 \%$ formalin and later transferred to $70 \%$ ethanol and $5 \%$ glycerine. Entire specimens were studied using interference contrast microscopy after clearing in phenol-alcohol or in glycerine. Following clearing, transverse sections cut by hand with a cataract knife were prepared from a female specimen to allow determination of the presence or absence of a synlophe. The cephalic, vulval, and caudal extremity of 2 female specimens, prepared for scanning electron microscopy (SEM) via critical point drying, were mounted on stubs and sputter-coated with gold-palladium. These specimens were examined with an Hitachi S-5700 electron microscope at $10 \mathrm{kV}$ at magnifications of 300-6,000 $\times$. In the description, measurements in $\mu \mathrm{m}$ were based on 10 males and 10 females, including the holotype and allotype. These data are presented as a range for all specimens, with the mean \pm 1 SD in parentheses. Sample sizes for measurements of spicules and eggs are 20 and 50, respectively. Description of the copulatory bursa and numbering of the bursal rays follows Chabaud et al. (1970) and DuretteDesset (1983). The type series and representative specimens were deposited in the U.S. National Parasite Collection, USDA, ARS, Beltsville, Maryland.

Specimens of other species were examined for comparative purposes as follows: (1) Libyostrongylus douglassii (Cobbold, 1882), USNM 40741, specimens designated as Ornithostrongylus douglassii collected by $\mathbf{H}$. O. Monnig, from the proventriculus (reported as stomach) of Struthio australis Gurney (now $S$. camelus australis) in Onderstepoort, South Africa; (2) $L$. douglassii, USNM 83439, 83827 from the proventriculus of $S$. camelus in Texas, collected by T. Craig; (3) L. douglassii, USNM 83828 , from the proventriculus of $S$. camelus in North Carolina, collected by S. Lloyd; (4) Libyostrongylus magnus Gilbert, 1937, International Institute of Parasitology, LSHTM no. 1317 from S. camelus in Ethiopia, collected by S. G. Solomon, February 1933 (these specimens were labeled as $L$. douglassii, identity redetermined in the current study); and (5) Paralibyostrongylus alberti (Berghe, 1943), USNM 61421, specimens designated as Libyostrongylus from the stomach of Dendrohyrax arbozéus adolphi in Africa, collected by L. van den Berghe. Additionally, the correct spelling for the species originally described by Cobbold (1882) is L. douglassii, in accordance with Article 33, Part d, of the International Code of Zoological Nomenclature, 3rd ed. Subsequent spellings by various authors, including $L$. douglasi and $L$. douglassi are incorrect. 
TABLE I. Strongylate nematodes of rheas and ostriches introduced to North America based on the holdings of the U.S. National Parasite Collection.

\begin{tabular}{|c|c|c|}
\hline & Rhea & Ostrich \\
\hline $\begin{array}{l}\text { Deletrocephalus* } \\
\quad \text { dimidiatus Diesing } 1851\end{array}$ & $\begin{array}{l}\text { Alabama } 66136 \ddagger \\
\text { Florida } 56054 \ddagger \\
\text { Missouri } 82709 \\
\text { Maryland } 82792\end{array}$ & - \\
\hline $\begin{array}{l}\text { Paradeletrocephalus } \\
\quad \text { minor (Molin 1861)* }\end{array}$ & Washington, DC $27266 \ddagger$ & \\
\hline $\begin{array}{l}\text { Codiostomum } \dagger \\
\text { struthionis (Horst, 1885) }\end{array}$ & - & Texas 83751 \\
\hline
\end{tabular}

* Host-specific parasite of rheas.

$\dagger$ Host-specific parasites of ostriches.

$\ddagger$ Reported from animal park or zoo or captive situations.

\section{RESULTS}

Single ostriches from captive flocks in North Carolina and Texas were found to be infected with libyostrongyline nematodes in the proventriculus and gizzard. Two species of $\mathrm{Li}$ byostrongylus were found at necropsy and included gravid female specimens of $L$. douglassii and mature males and gravid females of a previously unrecognized species described herein.

\section{Libyostrongylus dentatus $\mathrm{n} . \mathbf{s p}$.}

(Figs. 1-14)

General description: Trichostrongylidae, uncoiled, red in life. Cuticle with strong transverse striations; synlophe absent. Cervical papillae minuscule, situated near level of excretory pore. Esophagus attains maximum diameter in posterior. Cephalic vesicle absent. Mouth oval, with dorsal and ventral notches; cuticularized buccal ring well developed. Prominent dorsal esophageal tooth present. In apical view, 6 cephalic papillae with 2 pairs near the lateral amphids, and 4 externo-labial papillae are apparent.

Male: Small nematodes with a prominent copulatory bursa. Total length $6,448-8,550(7,522 \pm 646.59)$, maximum width anterior to prebursal papillae, 105-140 (117 \pm 10.03$)$. Esophagus 483-569 (519 \pm 31.57) long; maximum width attained at base, 36-55 (43 \pm 31.57$)$; ratio of total body length : esophageal length, 1:0.07. Nerve ring 192-304 (239 $\pm 33.48)$, excretory pore $265-369(333 \pm 33.12)$, and cervical papillae 265-387 (339 \pm 37.95) from anterior.

Copulatory bursa symmetrical, of type 1-3-1. Bilateral cuticular inflations at level of prebursal papillae. Rays 2 shorter than rays 3-6. Distally, tips of rays 3 curved anteriad toward rays 2; tips of rays 3 and 4 in proximity; distally tips of rays 5 and 6 parallel and separate. Rays 8 arise at base of dorsal ray. Origin of rays 9 symmetrical or asymmetrical, arising as lateral processes in posterior half of dorsal ray; tips extending to posterior margin of bursal membrane. Distal to origins of rays 9 , dorsal ray branches ending in terminal bifurcations of rays 10 and 11 , often extending into rounded lobe of bursal membrane.

Spicules subequal, alate, 140-159 (147 \pm 5.91$)$ long; with main shaft ending in rounded point capped by hyaline sheath; narrow ventral and dorsal processes arising at $64-70 \%(68 \pm 0.02 \%)$ of spicule length from anterior; spicule tips enveloped in membrane. Gubernaculum curved in lateral view, $49-59(54 \pm 3.40)$ in length. Genital cone complex, with single elongate " 0 " papilla ventral to cloaca, and paired " 7 " papillae contained in rounded plate, dorsal to cloacal aperture.

Female: Small nematodes with tail strongly curved ventrally. Total length $10,205-12,730$ (11,488 \pm 756.32$)$; maximum width, 120-150 $(137 \pm 9.23)$, attained near level of vulva. Esophagus 447-610 (545 \pm 46.75) long, maximum width attained at base, 36-55 (45 \pm 5.44$)$; ratio of total body length: esophageal length, 1:0.04-0.05 (0.05 \pm 0.01$)$. Nerve ring 200-285 (254 \pm 28.41$)$, cervical papillae 230-387 (323 \pm 55.05$)$, excretory pore $208-380(326 \pm 62.80)$ from anterior.

Ovaries didelphic. Vulva opens as transverse slit located sublaterally on the left or right side, slightly off ventral, at 9,525-11,835 from anterior extremity; at $92-93 \%$ of body length from anterior. Irregular, broad, cuticular inflations evident at level of vulva, disposed in ventral to sublateral fields adjacent to vulva, not extending anterior or posterior beyond vestibule; cuticular struts or other support not observed. Vagina vera short, dividing vestibule into long anterior and short posterior segments. Combined length of vestibule + sphincter 224-369 (290 \pm $40.21)$ in anterior; $117-255(210 \pm 38.66)$ in posterior. Infundibula near equal in length, 91-213 (141 \pm 32.64$)$ in anterior; 78-200 (131 \pm $33.57)$ in posterior. Total length of ovejector 702-933 (772 \pm 70.60$)$. Anterior uterine branch containing 29-71 $(55 \pm 14.36)$ eggs; posterior with 9-20 (14 \pm 3.33$)$. Eggs in early morula stage, $52-62(57 \pm 2.76)$ by $31-39(34 \pm 34)$. Tail $80-105(92 \pm 10.70)$ in length, strongly curled ventrally, with rounded, digitate tip; ventral cuticular inflation at level of anus.

Host: Type and only known host, $S$. camelus Linnaeus.

Habitat: Posterior proventriculus and under koilon lining of ventriculus; extending to caudal fourth of the ventriculus.

Specimens: Holotype male, USNM no. 83823, and allotype female, USNM no. 83824, from type host collected in North Carolina. Paratype specimens include 10 males and 9 females from North Carolina, USNM no. 83825; and 2 males from Texas, USNM no. 83752. Vouchers include 15 females from South Carolina, USNM no. 83826.

Locality: Reported from Lexington, North Carolina (type), and College Station, Texas; considered to represent a parasite introduced with the type host from sub-Saharan Africa.

Etymology: The specific name "dentatus" refers to the prominent esophageal tooth.

Remarks: Currently there is disagreement over primary diagnostic criteria for Libyostrongylus and Paralibyostrongylus (see Puylaert, 1967; Gibbons and Khalil, 1982; Durette-Desset, 1983). Specimens of nematodes described herein are provisionally referred to the former genus based on the relative positions of the tips of rays 3,4 , and 5 , where rays 3 and 4 are in proximity and distinctly separated from rays 5 (DuretteDesset, 1983). However, confusion over the adequacy of recognized criteria for these genera makes it necessary to provide comparisons among the 10 nominal species of Libyostrongylus (2) and Paralibyostrongylus (8).

Libyostrongylus dentatus $\mathrm{n}$. sp. is distinguished from congeners, $L$. douglassii and $L$. magnus by the presence of a prominent, dorsal esophageal tooth, structure of the dorsal ray and female tail, a sublateral vulva positioned in the far posterior near the tail, small dimensions of eggs in utero, and other meristic characters (Tables II, III; Figs. 15-22). In $L$. dentatus, the dorsal ray resembles that of Paralibyostrongylus as presented by Ortlepp (1939) with rays 9 branching anterior to the bifurcation terminating in rays 10 and 11 . Specimens of $L$. douglassii 

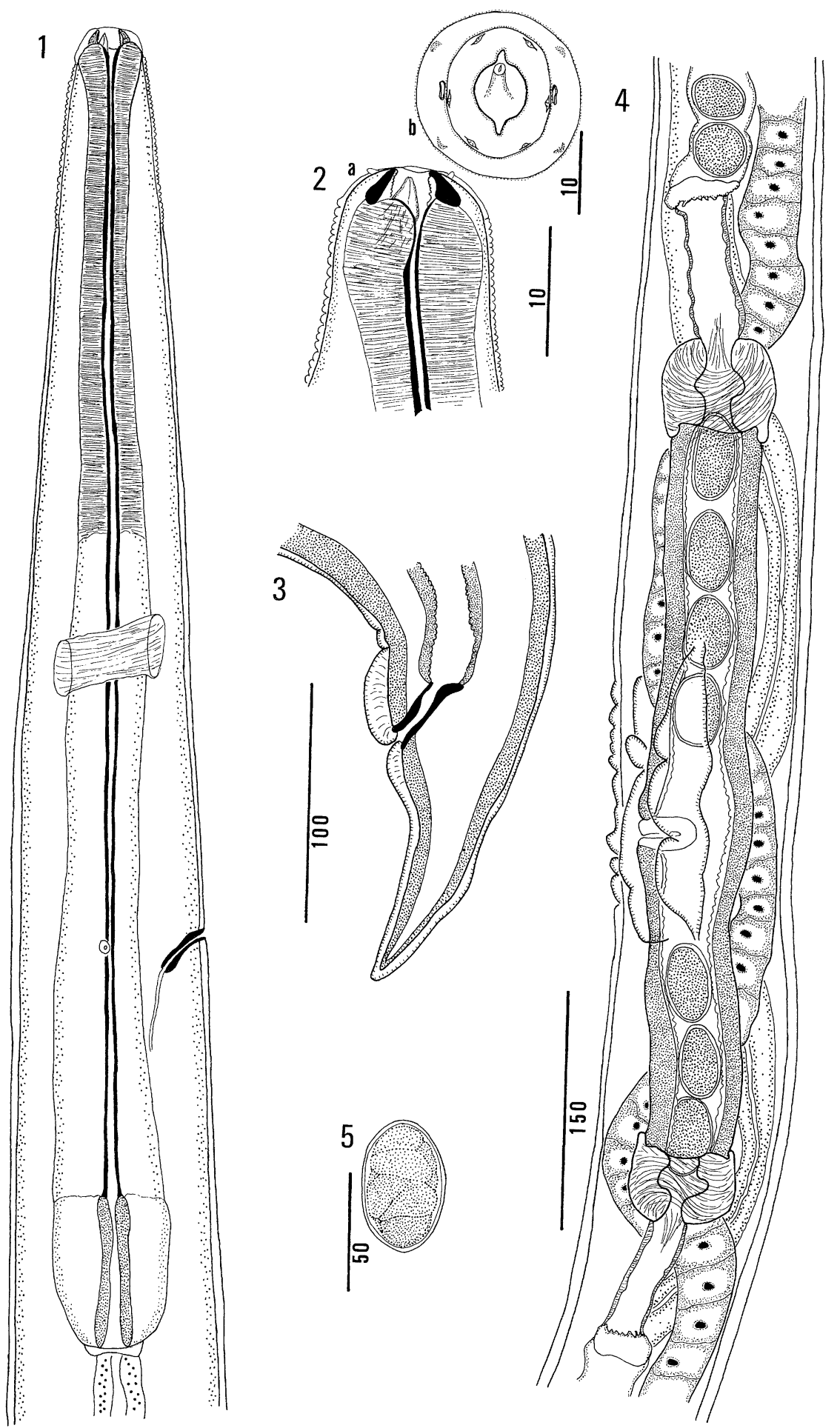

Figures 1-5. Libyostrongylus dentatus n. sp. from ostriches, Struthio camelus. Scale bars in $\mu \mathrm{m}$; same scale for Figs. 1 and 3.1 . Cephalic extremity and cervical zone in a female paratype. Right lateral view showing the structure of the esophagus, position of the nerve ring, excretory pore, and cervical papillae. 2a, b. Cephalic extremity of allotype female. (a) Right lateral view showing structure of buccal cavity with well defined buccal ring and prominent dorsal esophageal tooth; (b) apical view, drawn from SEM of paratype, with dorsal oriented toward top of plate showing tooth, structure of oral aperture, and distribution of cephalic and externolabial papillae. 3. Tail in a female paratype showing rounded tip and ventral cuticular inflations at anus. 4. Ovejector and vulva in allotype female in left lateral view. Note structure of infundibula, sphincters, and vestibule; sublateral position of the transverse vulva; and broad cuticular inflations bordering the vulva. 5. Egg in utero. 


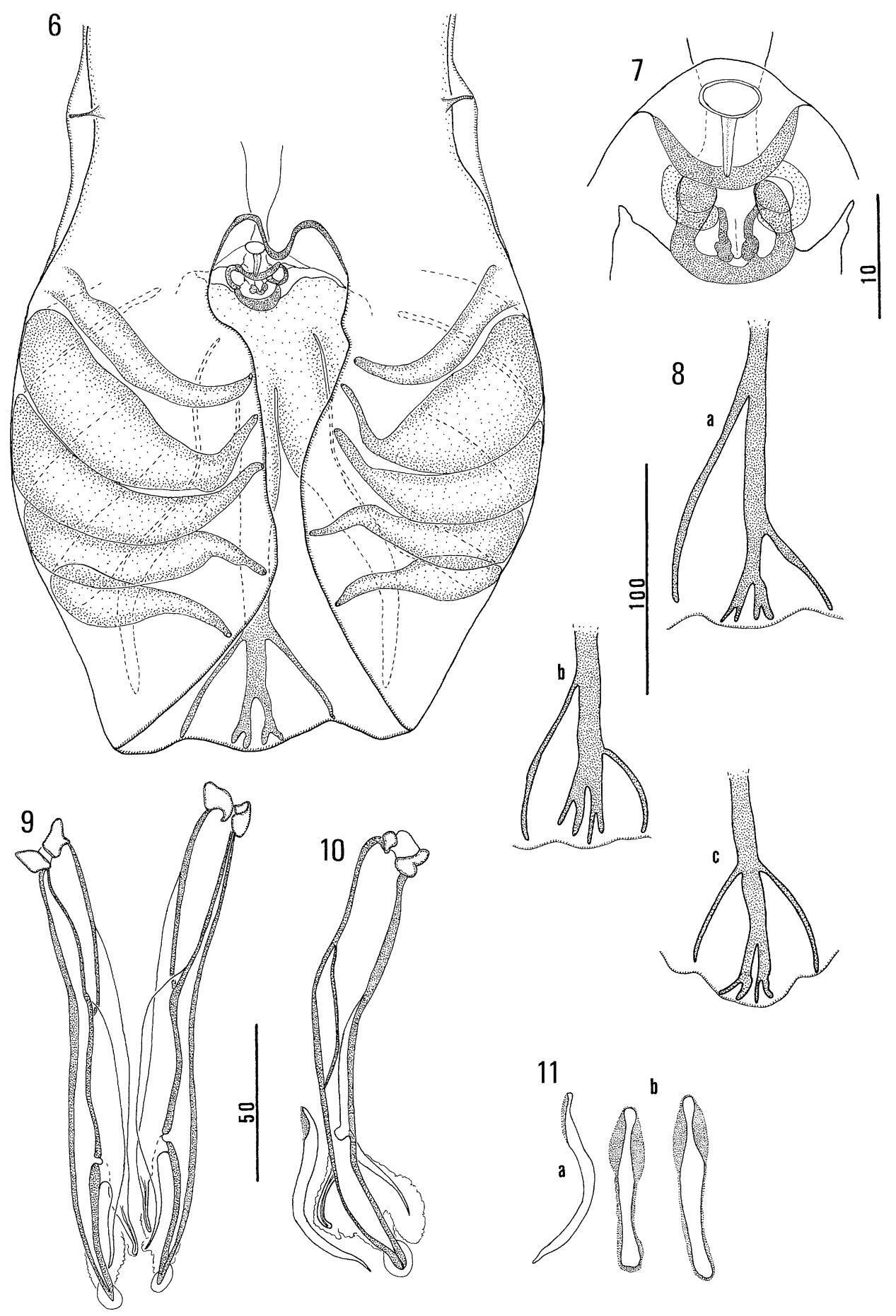

Figures 6-11. Libyostrongylus dentatus n. sp. from ostriches, Struthio camelus. Scale bars in $\mu \mathrm{m}$; same scale for Figs. 6 and 8; and Figs. $9-$ 11. 6. Bursa, ventral view in paratype showing prominent inflations at level of prebursal papillae (rays 1), position of lateral rays 3 and 4 with distal ends in proximity, rays 8 arising at base of dorsal ray, and rays 9 branching anterior to distal bifurcation of rays 10 and 11 at extremity of dorsal lobe. 7. Genital cone of holotype in ventral view showing single " 0 " papilla and complex "7" papillae and plate dorsal to cloacal aperture. 8a-c. Dorsal rays, ventral view, showing variation in symmetry and position of branches of rays 9,10 , and 11.9. Spicules in a paratype ventral view, showing hyaline cap at apex of primary shaft, and ventral and dorsal processes extending from ala. 10. Right spicule in lateral (external) view, showing structure of tips and relative position of gubernaculum. 11a, b. Gubernaculum in lateral (a) and ventral (b) views.

examined in the current study were found to have a dorsal esophageal tooth; however, this attribute was poorly developed.

Compared to $L$. douglassii, male and female specimens of $L$. dentatus are larger. Among females, $L$. dentatus has a substantially longer ove- jector, a greater number of eggs in the anterior uterus, a more posterior position of the vulva, markedly smaller eggs, a prominent cuticular inflation at the level of the anus, and a digitate tail (Tables II, III). Among males, spicule length is similar, but $L$. dentatus is readily iden- 


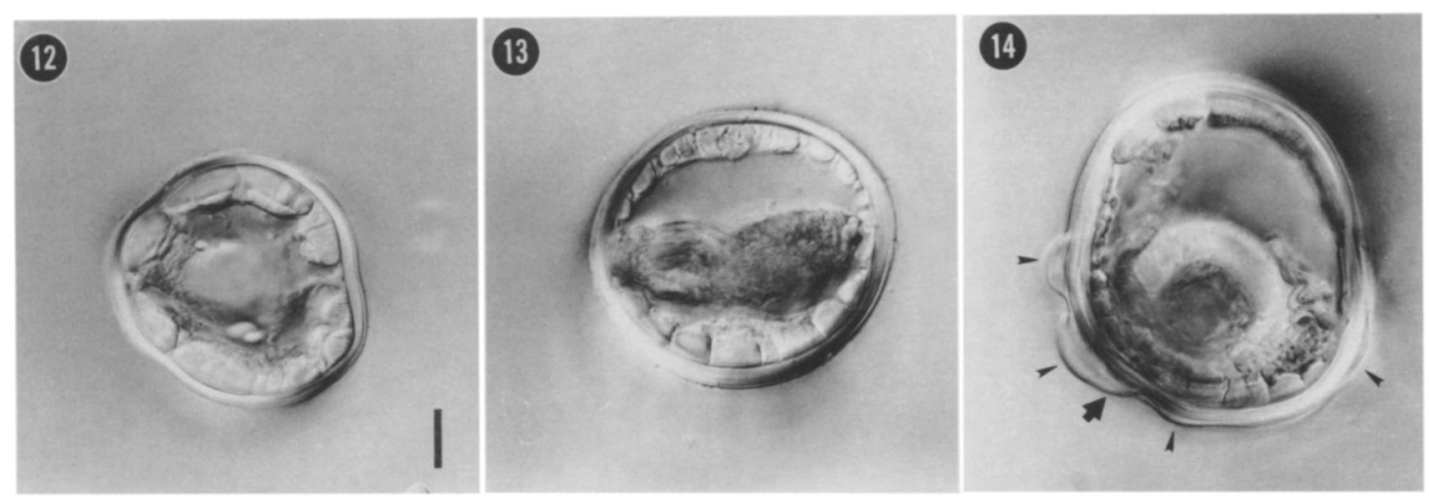

FIGUREs 12-14. Libyostrongylus dentatus $\mathbf{n}$. sp. Structure of cuticle in female specimen as seen in transverse section; same scale for all figures, bar $=20 \mu \mathrm{m}$. 12. Section at level of esophageal-intestinal junction. 13. Section at level of midbody. 14. Section at level of vulva (indicated by arrow) showing prominent cuticular inflations (pointers), not supported by cuticular struts, and without evidence of synlophe.

tified by the structure of the bursa and dorsal ray. Additionally, the presence of hyaline caps on the tips of the main shafts of the spicules in $L$. dentatus differs from the acutely pointed spicule tips of $L$. douglassii. Absence of marked sexual dimorphism, i.e., females smaller than males in $L$. magnus, smaller eggs, a more posterior vulva, a tail with cuticular inflation and smaller spicules distinguish $L$. dentatus from $L$. magnus (Tables II, III).

Published records of meristic data for $L$. douglassii require some comment (Tables II, III). Some measurements for L. douglassii in the literature are apparently incorrect. Thieler and Robertson (1915) indicated that the $50-\mu \mathrm{m}$ length of egg reported by Cobbold (1882) was an artifact of fixation; thus, the range of measurements for this character would not overlap substantially with $L$. dentatus. Additionally, $800 \mu \mathrm{m}$ for length of the ovejector reported by Skrjabin et al. (1954) represents an error in transcription from the work by Thieler and Robertson (1915). Consequently, the measurements presented for L. douglassii in the present study (Tables II, III) are compatible with those from the most detailed redescription by the latter authors.

Specimens of $L$. douglassii are recognized as particularly minuscule among the Libyostrongylinae. Thus, specimens of Libyostrongylus examined and redescribed by Durette-Desset and Denke (1978) are not compatible with all previous concepts for this species (Cobbold, 1882 Thieler and Robertson, 1915). These specimens differed substantially in the length of the body in males and females, dimensions of the esophagus (and relative length with respect to total body length), ovejector, spicules, and position of vulva (Tables II, III). Additionally, the females were reported as smaller than the males, a character only described for $L$. magnus. Thus, the material from ostriches in Somalia may be referable to $L$. magnus or a currently unrecognized taxon. Specimens of $L$. magnus examined in the current study were in agreement with the original description; sexual dimorphism was marked, eggs relatively large (near $85 \mu \mathrm{m}$ in length), with a long ovejector, and spicule length ranging from 230 to $240 \mu \mathrm{m}$.

Specimens of $L$. dentatus resemble species of Paralibyostrongylus in the structure of the dorsal ray based on criteria by Ortlepp (1939) and Gibbons and Khalil (1982). Specimens of $L$. dentatus are distinguished from all nominal taxa of Paralibyostrongylus with respect to the arrangement of bursal rays 3-5, where the tips of rays 4 and 5 are in proximity in species of the latter genus (Table IV). Among species of Paralibyostrongylus, only $P$. kalinae Durette-Desset et al., 1992, has a prominent esophageal tooth, but spicules and eggs are considerably larger than in L. dentatus. Only in P. cassonei Durette-Desset and Denke, 1978 are eggs similar in dimensions to those of $L$. dentatus, but spicules differ markedly in males of these species (Durette-Desset and Denke, 1978) (Table IV).

\section{DISCUSSION}

Libyostrongylinae were not historically represented in avian hosts endemic to North America (Durette-Desset, 1985). It is clear, however, that at least 2 species of Libyostrongylus are now likely to be widely distributed in the United States (Table I), having resulted from transport and introduction of infected hosts.

Libyostrongylus dentatus $\mathbf{n}$. sp. is considered to be a typical parasite of ostriches that should eventually be found in the historical range of the type host in sub-Saharan Africa. Due to the overall similarity and small size of $L$. dentatus and $L$. douglassii, it is suggested that the former species may have been overlooked previously. Difficulties in recovery of these nematodes would be compounded by their very small size and by localization in the proventriculus and under the koilon of the gizzard. Indeed, mixed infections of these species may not be uncommon and appear to be indicated by the observation of 2 distinct sizes of strongyle eggs, corresponding with these species (Table III), in ostriches from North Carolina, Mississippi, and Texas (pers. comm., L. G. Rickard and T. Craig). Although $L$. douglassii is known to be exceptionally pathogenic in ostriches (Thieler and Robertson, 1915; Button et al., 1993; Barton and Seward, 1993), the role of $L$. dentatus in morbidity and mortality remains to be determined. In the present paper, we provide the basis for clear differentiation of males and females of these species enabling accurate and rapid diagnosis (Tables II, III; Figs. 15-22). A third species, L. magnus, has not yet been reported in North America.

Specimens of $L$. dentatus can be unequivocally distinguished from species of Libyostrongylus and Paralibyostrongylus (Tables II-IV), but current morphological criteria at the generic level could allow placement in either genus (Gibbons and Khalil, 1982; Durette-Desset, 1983). Such could be construed as justification to reduce Paralibyostrongylus as a synonym of $\mathbf{L i}$ byostrongylus (see Chabaud, 1959; Le Van Hoa, 1959). However, the history of these genera and the distinct morphological characters on which they are based suggest that they are independent and that such a synonymy would be premature without detailed analysis.

The genus Libyostrongylus was established by Lane (1923) for some African trichostrongylids, with $L$. douglassii as type species from ostriches, and L. hebrenicutus Lane, 1923 from gorillas. Although superficially similar, these nematodes differed in the structure of the terminal bifurcations of the dorsal ray and in the pattern of the lateral rays (rays 3-5) of the copulatory bursa. This discrepancy led Ortlepp (1939) to establish the genus Paralibyostrongylus, naming $P$. vondwei Ortlepp, 1939 as the 
TABLE II. Comparison of male Libyostrongylinae from ostriches, including Libyostrongylus douglassii (Cobbold, 1882) (1-4), L. magnus Gilbert, 1937 (5), and $L$. dentatus $n$. sp.; ranges with mean values in parentheses.*

\begin{tabular}{|c|c|c|c|c|c|c|}
\hline Character & 1 & 2 & 3 & 4 & 5 & $\begin{array}{l}\text { Libyostrongylus } \\
\text { dentatus } \\
\text { n. sp. }\end{array}$ \\
\hline Esophagus length & $480-500$ & $480-500$ & 680 & $426-465$ & $800-900$ & $483-569$ \\
\hline \multicolumn{7}{|l|}{ Esophagus } \\
\hline $\begin{array}{l}\text { and oody lengtn } \\
\text { Nerve ring } \ddagger\end{array}$ & $\begin{array}{c}0.11 T \\
-\end{array}$ & $\begin{array}{c}0.10-0.11 T \\
-\end{array}$ & $\begin{array}{l}0.07 \dagger \\
250\end{array}$ & $\begin{array}{cl}0.08-0.11 & (0.10) \\
208-237 & (221)\end{array}$ & $\begin{array}{l}0.06 \dagger \\
418\end{array}$ & $\begin{array}{c}0.07 \\
192-304 \quad(239)\end{array}$ \\
\hline Excretory poreł & 300 & 300 & 440 & $278-325 \quad(298)$ & 633 & $265-369$ \\
\hline Tooth & Absent & Absent & Absent & Poorly developed & Absent & Present \\
\hline Spicule length & $140-150$ & $140-158$ & 170 & $122-148 \quad(134)$ & $220-240$ & $140-159$ \\
\hline \multicolumn{7}{|l|}{ Branching of spicule } \\
\hline$\%$ from anterior & $0.66 \dagger$ & $0.66 \dagger$ & $0.58 \dagger$ & $0.58-0.65 \quad(0.63)$ & $0.64 \dagger$ & $0.64-0.70 \quad(0.68)$ \\
\hline
\end{tabular}

type and referring $L$. hebrenicutus and $P$. nigeriae (Baylis, 1928) to the new genus. Libyostrongylus was distinguished by a dorsal ray that split anterior to the origins of rays 9 and the terminal bifurcations (rays 10 and 11 ), and in which the tips of the lateroventral (rays 3 ) and the externolateral (rays 4) rays were in proximity and the tips of the mediolateral (rays 5) were closer to those of the posterolateral (rays 6) rays. In contrast, Paralibyostrongylus was characterized by a dorsal ray in which rays 9 branched anterior to the terminal bifurcations ending in rays 10 and 11 and in which the tips of rays 4 were in proximity to those of rays 5 .

Skrjabin et al. (1954) used the structure of the dorsal ray as

TABLE III. Comparison of female Libyostrongylinae from ostriches, including Libyostrongylus douglassii (Cobbold, 1882) (1-4), L. magnus Gilbert, 1937 (5), and $L$. dentatus $\mathbf{n}$. sp.; ranges with mean values in parentheses.*

\begin{tabular}{|c|c|c|c|c|c|c|c|c|}
\hline$\frac{\text { Character }}{\text { Total length }}$ & 1 & 2 & 3 & \multicolumn{2}{|l|}{4} & 5 & \multicolumn{2}{|c|}{$\begin{array}{l}\text { Libyostrongylus } \\
\text { dentatus } \\
\text { n. sp. }\end{array}$} \\
\hline Esophagus length & $480-500$ & $480-500$ & 550 & $447-471$ & (458) & $684-756$ & $447-610$ & $(545)$ \\
\hline \multicolumn{9}{|l|}{ Esophagus } \\
\hline and body length & $0.09 \dagger$ & $0.09 \dagger$ & $0.07 \dagger$ & $0.08-0.09$ & $(0.08)$ & $0.07-0.09 \dagger$ & $0.04-0.05$ & $(0.05)$ \\
\hline Excretory poreł & 300 & 300 & 390 & $198-283$ & $(265)$ & 633 & $208-380$ & (326) \\
\hline Tooth & Absent & Absent & Absent & \multicolumn{2}{|c|}{ Poorly developed } & Absent & \multicolumn{2}{|c|}{ Present } \\
\hline Vulva position & Ventral & Ventral & Ventral & \multicolumn{2}{|c|}{ Ventral } & Ventral & \multicolumn{2}{|c|}{ Sublateral } \\
\hline Vulva & & & & & & & & \\
\hline$\%$ body length $\ddagger$ & $0.85 \dagger$ & $0.86 \dagger$ & $0.77 \dagger$ & \multicolumn{2}{|c|}{0.86} & $0.69-0.77 \dagger$ & $0.92-0.93$ & $(0.93)$ \\
\hline Ovejector length & $800 \S$ & 300 & 1,365 & $377-463$ & $(427)$ & - & 702-933 & $(772)$ \\
\hline Eggs, no. anterior & - & 30 & - & $18-29$ & (21) & - & $29-71$ & (55) \\
\hline Eggs, no posterior & - & 15 & - & $6-13$ & (9) & - & $9-20$ & (14) \\
\hline
\end{tabular}

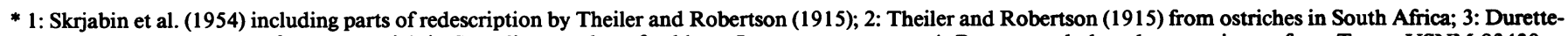
Desset and Denke (1978) from an ostrich in Somalia; may be referable to $L$. magnus, see text; 4: Present study based on specimens from Texas, USNM 83439; $n$ $=5 ; n=25$ for eggs; 5 : Description by Gilbert (1937) reproduced by Skrjabin et al. (1954).

$\dagger$ Estimated from written description or published figure.

$\S$ The $800 \mu \mathrm{m}$ length appears to represent a mistake in transcription of part of Theiler and Robertson (1915) by Skrjabin et al. (1954).

$\|$ An egg length of $50 \mu \mathrm{m}$ in $L$. douglassii is unreliable and is considered to be a fixation artefact in the type material of Cobbold (1882) as suggested by Theiler and

Robertson (1915).

$\ddagger$ Measured from anterior. 


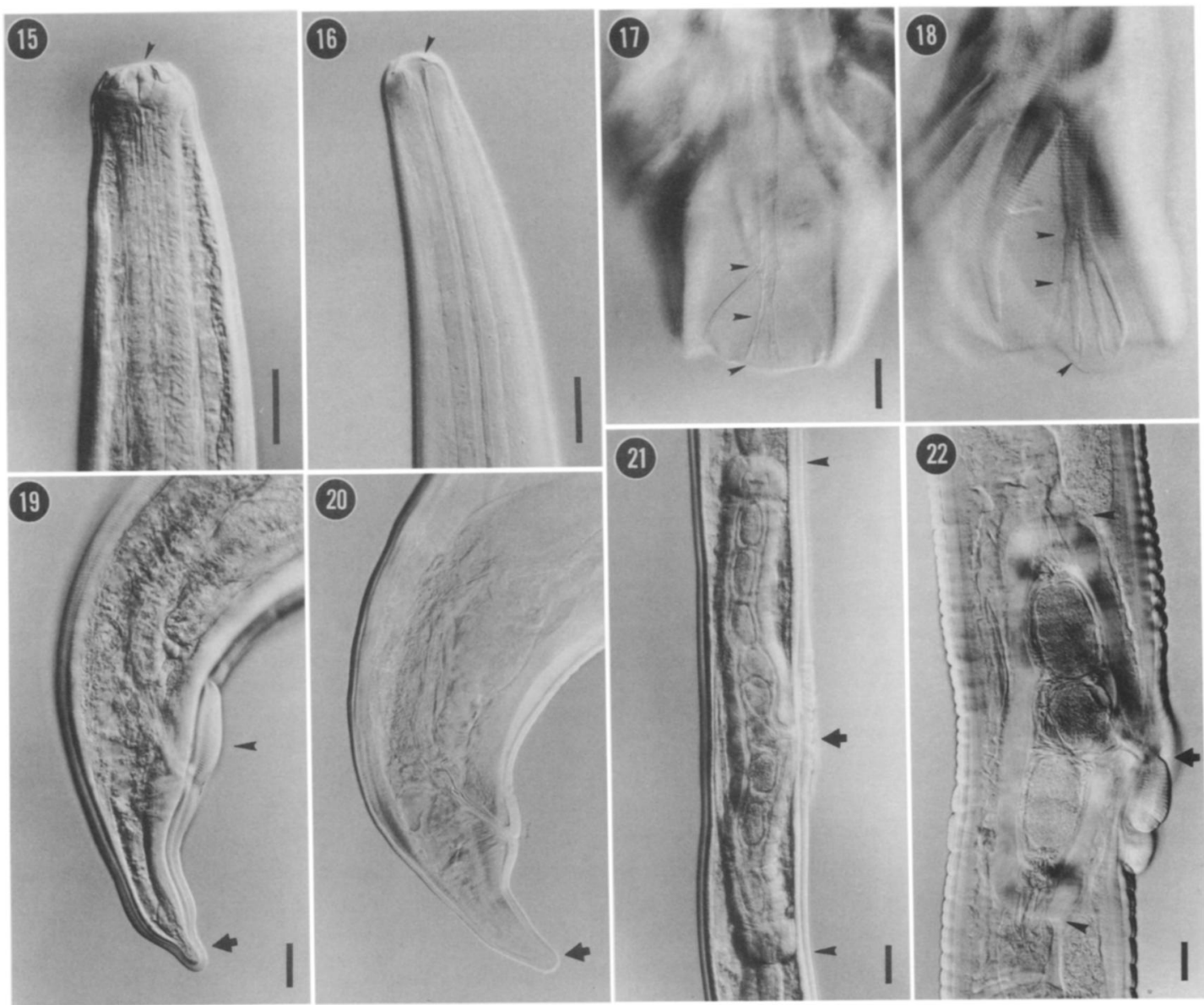

FIGURES 15-22. Comparison of key morphological characters for the identification of $L$. dentatus n. sp. and L. douglassii; scale bars $=20$ $\mu \mathrm{m}$, unless indicated otherwise. 15. Cephalic extremity of $L$. dentatus showing prominent esophageal tooth, lateral view (pointer). 16. Cephalic extremity of $L$. douglassii showing minuscule esophageal tooth (pointer). 17. Dorsal ray in $L$. dentatus showing characteristic pattern of bifurcations (pointers). 18. Dorsal ray in $L$. douglassii (same scale as Fig. 17) showing typical pattern of bifurcations (pointers). 19. Tail in female of $L$. dentatus, with prominent cuticular swelling at level of anus (pointer) and digitate tip (arrow), lateral view. 20. Tail in female of $L$. douglassii (same scale as Fig. 19) lacking cuticular inflation, and with rounded tip (arrow). 21. Relatively long ovejector of $L$. dentatus (scale bar $=40 \mu \mathrm{m}$ ) showing region of sphincters and vestibule (between pointers) and position of vulva (arrow); note irregular inflations at level of vulva and numerous eggs in vestibule. 22. Short ovejector of $L$. douglassii showing region of sphincters and vestibule (between pointers) and position of vulva (arrow); note irregular inflations near vulva and few eggs in the vestibule.

the primary criterion to separate the genera. However, Chabaud (1959) and Le Van Hoa (1959) regarded the genera as synonyms. The later contention was supported by the recognition of several species which appeared intermediate to Libyostrongylus and Paralibyostrongylus, e.g., L. alberti and L. bathyergi (Ortlepp, 1939), which had a "Libyostrongylus-type" dorsal ray, but "Paralibyostrongylus-type" lateral rays (Table IV).

Puylaert (1967) disregarded the structure of the dorsal ray as a diagnostic or phylogenetic character due to its putative variability among strongylate nematodes. Instead, generic designation was based on the relationships and position of the rays 3,4 , and 5. Secondarily, it was noted that species of Libyostrongylus were parasites of ratites, whereas Paralibyostrongylus were parasites of archaic mammals, lagomorphs, and primates; however, host association is not a valid generic criterion. This system was adopted by Durette-Desset and Chabaud (1977) with the establishment of the subfamily Libyostrongylinae and in the keys developed by Durette-Desset $(1983,1985)$ for the Tri- chostrongylidae. Under this system, 3 species currently referred to Paralibyostrongylus have a "Libyostrongylus-type" dorsal ray (Table IV). Among these species, P. kalinae exhibits a lateral ray pattern in which rays 3,4 , and 5 are equidistant (DuretteDesset et al., 1992), and thus is not clearly definable as Paralibyostrongylus. The pattern of the lateral rays in species of Libyostrongylus is consistent with the original generic diagnosis (Ortlepp, 1939) and that of Puylaert (1967); however, in specimens of $L$. dentatus the dorsal ray is of the "Paralibyostrongylus-type" (Table IV).

In contrast to the system presented by Durette-Desset (1983), keys developed by Gibbons and Khalil (1982) relied solely on the pattern of bifurcations of the dorsal ray to separate Libyostrongylus and Paralibyostrongylus. Thus, based on this criterion, $P$. kalinae, $P$. alberti, and $P$. bathyergi would be placed in Libyostrongylus, and L. dentatus would be placed in Paralibyostrongylus (Table IV).

Resolution of this problem is beyond the scope of the present 
TABLE IV. Comparison of some diagnostic characters among Libyostrongylus spp. and Paralibyostrongylus spp.*

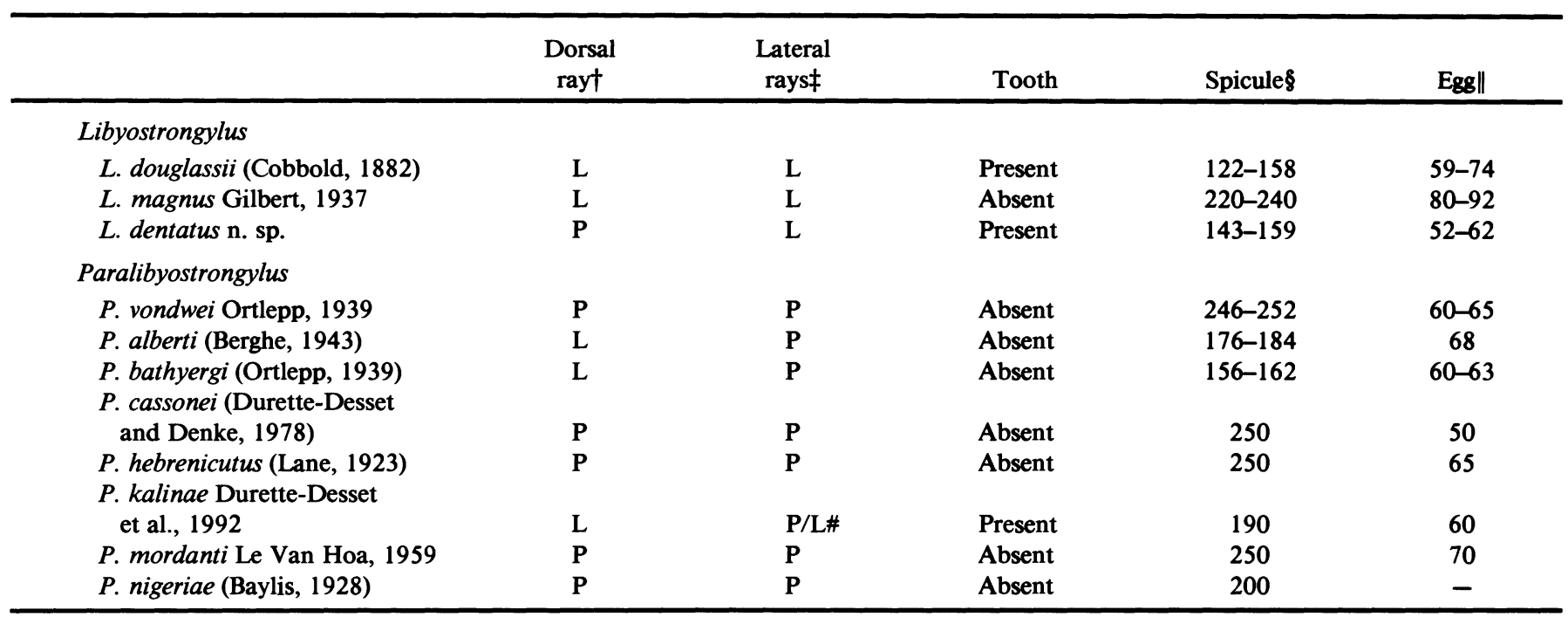

* From original descriptions and/or detailed redescriptions: Cobbold (1882), Theiler and Robertson (1915), Lane (1923), Baylis (1928), Ortlepp (1939), Skrjabin et al. (1954), Le Van Hoa (1959), Durette-Desset and Denke (1978), Cassone et al. (1992), and Durette-Desset et al. (1992).

$\dagger \mathrm{L}=$ "Libyostrongylus type" and $\mathrm{P}=$ "Paralibyostrongylus type" according to Ortlepp (1939) and Gibbons and Khalil (1982).

$\ddagger \mathrm{L}=$ "Libyostrongylus type" (ray 4 closer to ray 3) and $\mathrm{P}=$ "Paralibyostrongylus type" (ray 4 closer to ray 5) according to Puylaert (1967) and Durette-Desset (1983).

$\$$ Length of spicules; not including measurement reported by Durette-Desset and Denke (1978) for L. douglassii.

II Length of egg; not including data from Cobbold (1882) for $L$. douglassii.

\# In P. kalinae, figures indicate that ray 4 is equidistant from rays 3 or 5, thus not typical of either Libyostrongylus or Paralibyostrongylus (see Durette-Desset et al., 1992).

work, and synonymy of these genera is not currently justified. Libyostrongylus dentatus is provisionally referred to this genus pending phylogenetic analysis of the Libyostrongylinae. Such analysis should reveal the relative importance of these discordant characters, among other morphological attributes, in defining monophyletic taxa. Either the dorsal ray will be found to be diagnostic (with variable position of the lateral rays) (Gibbons and Khalil, 1982), or the pattern of lateral rays will be useful in definition of these genera (with variation in bifurcations of the dorsal ray) (Durette-Desset, 1983). Analysis of the 11 species relegated to either Libyostrongylus or Paralibyostrongylus has direct implications for understanding the coevolution of these nematodes in ratites, archaic rodents, lagomorphs, and primates. Interpretation hinges on recognizing monophyly for these genera or the possibility that at least Libyostrongylus or Paralibyostrongylus could be paraphyletic.

The potential for widespread dissemination of Libyostrongylus spp. among ostriches is indicated by the history of the female (type host) from North Carolina. This 5.5-yr-old bird had been hatched and raised near Houston, Texas, where it was housed until 1990. In that year, it was transported to Oklahoma and in 1993 to North Carolina where both $L$. douglassii and L. dentatus now appear to be established. In this regard, 2 other birds are now known to be infected (based on fecal examination) on the farm near Raleigh, North Carolina. A more detailed history for these parasites in North Carolina is in preparation.

The presence of $L$. dentatus in flocks from Texas suggests that this may have been the area of origin for this nematode once it was established in North America. This is suggested because the parasite is present in both Texas and North Carolina, and the distribution would be compatible, based on the history of the type host, with transport from the former locality. Additionally, it is of interest that birds from some flocks in Texas had been imported directly from Tanzania in the late 1980s (T. Craig, pers. comm.). This latter region may represent the historical distribution of $L$. dentatus in sub-Saharan Africa and may correspond with the range of the subspecies Struthio camelus massaicus Neumann (see Freitag and Robinson, 1993). Additionally, L. magnus appears to have been found thus far only in the nominate subspecies, $S$. camelus camelus Linnaeus, in Ethiopia and possibly the Sudan. In contrast, L. douglassii was originally described from South Africa and may be endemic or more common in southern Africa in $S$. camelus australis Gurney (Cobbold, 1882; Thieler and Robertson, 1915). The possibility of a disjunct distribution for these species of Libyostrongylus coinciding with the contemporary subspecies of ostriches that radiated during the Pliocene and Pleistocene (see Freitag and Robinson, 1993) remains to be evaluated. However, extensive transport of ostriches in Africa over the past century could confound elucidation of the historical host and geographic distributions of this fauna.

\section{ACKNOWLEDGMENTS}

We thank Thomas Craig for specimens of Libyostrongylus spp. from Texas and for providing information on the current status of ratites in the United States. Lynda Gibbons of the International Institute of Parasitology kindly loaned specimens of Libyostrongylus magnus for examination. Arthur Abrams assisted in preparation of the specimens for study. Patricia Pilitt kindly prepared transverse sections of female $L$. dentatus. Charles Murphy of the Electron Microscopy Laboratory, USDA, ARS, Beltsville, assisted in preparation of the specimens for SEM; SEM was conducted by C. Murphy and J. R. Lichtenfels. We thank anonymous reviewers for comments that improved the manuscript. 


\section{LITERATURE CITED}

Barton, N. J., AND D. A. SewARD. 1993. Detection of Libyostrongylus douglassi in ostriches in Australia. Australian Veterinary Journal 70: 31-32.

BAYus, H. A. 1928. On a collection of nematodes from Nigerian mammals (chiefly rodents). Parasitology 20: 280-304.

Button, C., N. J. Barton, P. I. Veale, and D. J. Overend. 1993. A survey of Libyostrongylus douglassi on ostrich farms in eastern Victoria. Australian Veterinary Journal 70: 76.

Cassone, J., P. N. Vuong, AND M. C. DuRette-Desset. 1992. Cycle biologique de Paralibyostrongylus hebrenicutus (Nematoda: Trichostrongylidae). Annales de Parasitologie Humaine et Comparée 67: 33-41.

Chabaud, A. G. 1959. Remarques sur la systematique des Nématodes Trichostrongyloidea. Bulletin Société Zoologique, France 84: 473483.

, F. Puylaert, O. Bain, A. J. Petter, and M. C. DURETte-Desset. 1970. Remarques sur l'homologie entre les papilles cloacales des rhabdites et les côtes dorsales des Strongylida. Comptes Rendus Hebdomadaire des Séances de l'Academie des Sciences, Paris 271: 1771-1774.

Clay, T. 1957. The Mallophaga of birds. Premier Symposium sur la spécificité parasitaire des parasites de vertébrés. Union Internationale des Sciences Biologiques 32: 120-158.

Cobsold, T. S. 1882. New entozoon from the ostrich. Journal of the Linnean Society 16: 184-188.

DURETTE-DESSET, M. C. 1983 . Keys to the genera of the superfamily Trichostrongyloidea. No. 10. In CIH keys to the nematode parasites of vertebrates, R. C. Anderson and A. G. Chabaud (eds.). Commonwealth Agricultural Bureaux, Farnham Royal, England, 86 p. . 1985. Trichostrongyloid nematodes and their vertebrate hosts: Reconstruction of the phylogeny of a parasitic group. Advances in Parasitology 24: 239-306.

- AND A. G. Chabaud. 1977. Essai de classification des Né- matodes Trichostrongyloidea. Annales Parasitologie Humaine et Comparée 52: 539-558.

, AND M. DENKE. 1978. Description de nouveaux Nématodes parasites d'un Lièvre africain et compléments à l'étude morphologique de quelques Trichostrongylidae. Bulletin Muséum National d'Histoire naturelle 354: 331-347.

, A. G. Chabaud, R. W. Ashrord, T. Butynski, and G. D. F. REID. 1992. Two new species of Trichostrongylidae (Nematoda: Trichostrongyloidea), parasitic in Gorilla gorilla beringei in Uganda. Systematic Parasitology 23: 159-166.

Freitag, S., AND T. J. Robinson. 1993. Phylogeographic patterns in mitochondrial DNA of the ostrich (Struthio camelus). Auk 110: 614-622.

GibBons, L., AND L. F. KhallL. 1982. A key for the identification of genera of the nematode family Trichostrongylidae Leiper, 1912. Journal of Helminthology 56: 185-233.

LANE, C. 1923. Some Strongylata. Parasitology 15: 348-364.

LE VAN HoA. 1959. Un nouveau Trichostrongylidae de Lièvre africain. Annales de Parasitologie Humaine et Comparée 33: 625-630.

OrTLEPP, R. J. 1939. South African helminths, Part VI. Some helminths, chiefly from rodents. Onderstepoort Journal of Veterinary Science and Animal Industry 12: 75-101.

PUYLAERT, F. 1967. L'Athéruee hôte naturel de Paralibyostrongylus hebrenicutus (Lane, 1923). Considérations sur les generes Libyostrongylus et Paralibyostrongylus (Nématodes). Bulletin du Muséum National d'Histoire naturelle 38: 921-927.

SkrJabin, K. I., N. P. Shikhobalova, AND R. S. Shul'ts. 1954. Trichostrongylids of animals and man. Akademia Nauk SSSR, Moscow. [English translation by Israel Program for Scientific Translations, Jerusalem, 1960, 704 p.]

ThIELER, A., AND W. RoberTson. 1915. Investigations into the lifehistory of the wire-worm in ostriches. Reports of the Director of Veterinary Research, Union of South Africa Department of Agriculture, nos. 3 and 4: 293-336. 